\title{
The Integration of Traditions, Technologies, Translations and Transformations in Banana Tree Fiber Designs
}

abstract This article discusses innovations in the knowledge-building process on designs utilizing braided banana tree fibers. It is part of a broader study on emergency design, with a case study in the municipality of Eldorado, in the Ribeira Valley of Brazil, an area recurrently affected by floods. It focuses on the project development of partitions for temporary shelters with a collaborative design process that unites researchers, local authorities, nongovernmental organizations and quilombola communities (Brazilian maroon communities). This text is structured into four parts: Quilombola Traditions and Natural Disasters; Fiber Technologies and the Myths of Creation; Translations and Possible Dialogues between Stakeholders; and Transformations in Three Integrated Actions. The first part presents the quilombola community and questions traditional techniques that have not yet solved their recurrent problems. The second part describes local know-how, and reflects on the craft of the artisans who work with the fiber. The third part discusses how to empower the population to innovate with quality and efficiency, while being sustainable over time. The fourth part proposes the implementation of transformations in three actions as a way to make the dissemination of concepts applicable to other areas. The benefits of the proposed interaction are based on the eco-development concept coined by lgnacy Sachs in 1980, where strengthening local development occurs through the inclusion of everyone in the decision-making process.

keywords emergency design, banana tree fiber, eco-development, quilombola communities, temporary shelters

\section{Introduction}

\section{Quilombola Traditions and Natural Disasters}

The municipality of Eldorado, located in the Ribeira Valley in the southeastern region of Brazil, derives its name from the fact that gold was mined there during the seventeenth century, a time when the country was still a colony of Portugal. After the decline of the gold mining period, which was a period based on slave labor, former slaves began to occupy the land and started planting banana crops, which in the zoth century became the region's chief economic product. The Ribeira Valley concentrates most of the communities living where the quilombos were located along Brazil's Atlantic Forest. These are living communities of Afro-Brazilians, the descendants of enslaved Africans. With the end of slavery, these groups organized themselves under local leadership, and today their cultural expression is one of great diversity, though not very well-known throughout Brazil. It was only with the 1988 Constitution that their ownership of land - usually in rural areas - was recognized. 
Due to the town's location by the banks of the Iguape River, however, the people of Eldorado are often affected by floods. Prolonged and heavy rains increase the water level, and due to the increased water flow, the river can reach levels up to ten meters above normal. The waters reach homes by the river banks in recurring natural disasters (Amaral, Gutjahr, 2012). During the floods, the population moves to temporary shelters: public buildings such as churches, schools and community centers adapted for use as shelters during the emergency period.

Since 2010, the author of this article has coordinated, together with her research team NOAH - Habitat Center without Borders, a research project entitled "Emergency Design: Furniture and Equipment for Temporary Shelters with Groups Affected by Disasters Related to Rainfall." This project designs solutions and creates prototypes that reflect the true demands and aspirations of the people involved in the emergency situations. As part of this project, the PhD professor Lara Leite Barbosa and two undergraduate students with scholarships through the University of São Paulo Culture and Extension Program have been carrying out research aimed at producing a manual for the production of building components made from plant fibers as a way to train and empower those affected by the floods. The research involves different educational and research institutions, government officials and local authorities, non-governmental organizations, partner companies, and the individuals affected by the floods in the municipality of Eldorado.

Because of the recurrence of the catastrophes, the population has developed disaster response mechanisms, though they are often implemented in an improvised and disorganized manner, making the recovery phase more difficult. Now, are there any previously used solutions that utilize local knowledge in the case of flooding? In terms of territory occupation, quilombolas very wisely set up in the valley areas less prone to flooding, for they were familiar with the river's behavior. The urban population is most affected, with about 70\% occupancy in the risk area, as mapped in 2012.

Traditionally, everyday objects such as taboa mats and piri were used in quilombola homes, and some are still produced today. The decrease in agricultural labor has reduced the demand for traditional objects. However, different objects and crafts made from natural fibers are now being requested by visitors and can be found for sale at fairs in other cities.

The intervention actions aim to provide resilience for the population. Local development can be strengthened by combining traditional and innovative technologies.

\section{Fiber Technologies and the Myths of Creation}

"The story of Moses - the one saved from the waters, Egyptian prince, savior of the chosen people, God's messenger, bringer of the tablets of law, the Ten Commandments - has a typical character. He is placed in the waters (primordial and generating fluid) inside a basket. This saves his life, determines his proper education and livelihood and leads him, in a determined way, to his destination as man's guide and officiating priest of the divine will." (Klintowitz, 1985: 30)

In different civilizations throughout human history, we consistently find the presence of basketry made from woven natural fibers. This is not only because indigenous populations commonly use baskets for day to day use and rituals, but also because they reflect the resources available in nature that can be utilized through techniques handed down from generation to generation. 
The entire process is endowed with a knowledge acquired through a deep connection with nature. In Brazil, a country of exuberant natural beauty, there is a huge variety of fibers such arumã, babaçu, banana, carnauba wax, vine, embira, ouricuri, taboa, and taquara (bamboo), among others. This article presents a survey conducted on banana tree fiber, which is widely used in the manufacture of everyday objects in the quilombos of the Ribeira Valley. The fibers must be harvested on the third day after the full moon, when the moon begins to wane. According to Esperança Santana Ramos Rosa, a 68-year-old artisan who lives at Quilombo Sapatu, "one has to plant and cut during the waning phase of the moon" n order to avoid carcoma, a type of beetle that lives off the banana tree. Generally speaking, the man is the one who reaps the resources of the forest. "The first job is to find a banana tree in the field.

Then we cut down the full tree and take home as much weight as we can handle. The banana tree gives fruit only once. In the past, we used to pick the bananas and leave the tree in the field - we did not know what to do with it. Now we use the straw to make crafts." (Andrade Tatto 2013: 199).
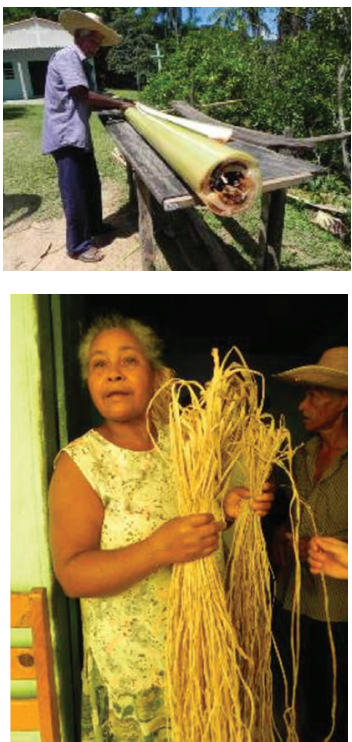

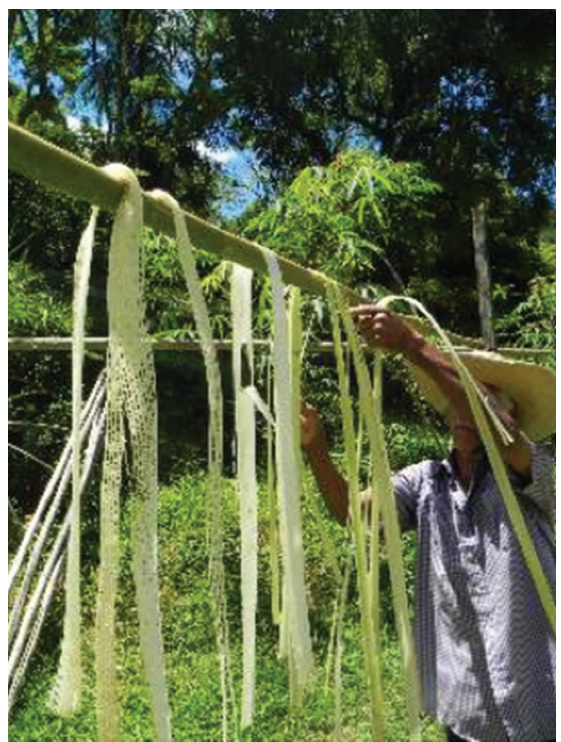

After harvesting, the fiber is cut to produce three kinds of straw, which John Rosa, 72, the husband of Mrs. Esperança, refers to as the "steak, strip loin and lace" (Fig. 1). The steak is the thinnest strip, cut from the narrowest part. The strip loin is a thicker cut, made next. The lace is obtained by cutting the part that has few alveoli and that, when unfilled, have a velvety texture once dry. Drying time will range from one to three days in the hot sun, depending on the type of cut. (Fig.2)

The dry fibers (Fig. 3) can be treated by spraying them with eucalyptus oil, canola oil and a mild detergent to protect them from carcoma and fungus. Depending on what is to be built, one can dye the fibers or even varnish them to darken their color.

Banana tree fiber is braided at home, using one's loom and creativity. Artifacts produced include mats, baskets, sieves, brooms, cushions, place mat sets, bags, hats, earrings and
Figure 1.

(left up) A cut of the banana tree by John Rosa at Quilombo Sapatu (2013), photo by Lara Leite Barbosa.

Figure 2.

(right) John Rosa hanging the three types of fibers on the clothesline to dry in the sun (2013), photo by Lara Leite Barbosa.

Figure 3 .

(left down)

Esperança Santana Ramos Rosa holds the three types of banana tree fiber already dry (2013), photo by Lara Leite Barbosa. 
belts. Both the men and women are craftsmen, and the goods are either for themselves or to be sold as crafts not only in the municipality, but also at fairs in major cities.

In the earliest days, the traditions of the quilombola people included passing on this knowledge from father to son, through the reproduction of daily routines. The need to market goods in order to make a living changed not only the type of crafts being produced, but also how they are made. Once in a while, courses are offered to the communities, where residents can learn new techniques and experiment with other possibilities for shapes and objects.

To what extent do innovations interfere with the artisan's craft? It is not about bringing aid to a community in need, as though they were unable to care for themselves. Their way of life, simple, but full of cultural and natural riches, proves its extraordinary value. The artisan's craft, being a commercial activity, represents not only a way to improve their economic situation, but is also a form of social inclusion.

\section{Translations and Possible Dialogues between Stakeholders}

Workshops inspired by design thinking methodology serve to determine the type of intervention action to be taken in the places where the population is affected by floods. In order to understand the main problems and solutions of those affected, the research team NOAH, Habitat Center without Borders, organized two collaborative workshops in Eldorado, one in 2011 and another in 2012. On these occasions, we had the opportunity to dialogue with the population, which confirmed the residents' interest in the proposal. Ideas for different projects were collected, particularly for partitions made from plant fibers for the existing shelters, and partitions for new temporary public toilets that will be made with a plate of banana tree fiber.

Here it should be noted that a channel of communication with the project's public already exists, as well as good relationships with the agencies connected to these people: CRAS - Social Assistance Reference Center, from the municipality; Civil Society Non-for-Profit Organization; and the CEPEC - Centre for Education, Professionalization, Entrepreneurship and Citizenship, which represents the rights and interests of traditionally excluded groups, mainly, the quilombola communities.

People in the area who have experienced homelessness are a population very much in need, since their rates of socioeconomic development are below the average of the state of São Paulo. Nevertheless, there is also an unexplored potential in the area, one which we intend to harness: banana tree fiber. The project aims to generate subsidies that make reconstruction, following the losses caused by floods, easier. At this stage of the research, we have studied the feasibility of using banana fiber techniques to develop building components on a larger scale. This approach aims to enhance regional production, maintain the people's cultural values and ensure that the invested resources remain in the region.

As a result of our interaction, we propose design revisions of the crafts made with braided fiber. The current weft will need to be strengthened and enhanced in order to form rigid panels. Innovations proposed for the braided fiber process include the use of a wooden structure to attach the wefts, which would be produced modularly according to the dimensions of a small loom. After the new work processes have been tested by the researchers, managers and artisans, the NOAH group will produce a manual on partition production to be forwarded to local leaders and project participants. The aim 
is to promote training courses in order to disseminate the results to a larger number of people in the community. At the end of the research project, continuity will occur through a partnership with the social and technological incubator, or even through a partnership with a factory in the industrial district of Eldorado, where banana tree fibers are currently manufactured for papermaking.

It is to be, however, a relationship in which there is no dominant side: it will be a two- way street where everybody wins:

"Serving is different from helping. Helping is based on inequality; it is not a relationship between equals... Service is a relationship between equals... Helping incurs debt. When you help someone they owe you one. But serving, like healing is mutual. There is no debt." (Remen apud Nelson; Stolterman, 1985: 25)

\section{Transformations in Three Integrated Actions}

Over the last twenty years, we have seen major climate changes that reverberate throughout multiple socio-cultural, economic and environmental realms. Human intervention actions regarding land use, occupation and exploitation have intensified to the point of causing an environmental imbalance.

How can we change this situation or at least minimize the damages caused by natural disasters? We suggest the promotion and integration of three actions, based on the basic precepts of eco-development stated by Ignacy Sachs (1993):

\section{1) Design networks with equality}

Relationships between researchers, consultants, the population and leaders are most fruitful when based on the exchange of favors in which everybody wins. To achieve this commitment, it is necessary for everyone to feel like they are part of the project. Everyone must be present, living together in the context, and being part of the project.

\section{2) Do more with less}

Local labor should be used to develop local materials and techniques. We highlight the importance given by Sachs to the ecological dimension: it should be integrated and coordinated with the project's human dimensions, doing so in an interdisciplinary manner. The project must develop appropriate technologies that allow for the absorption of the best of each ecosystem's human and natural variables.

3) Integrate the community during, not after, the project.

Guarantee access to all in the decision-making process in order to preserve diversity and cultural identity. Conduct the project together with a local leader who can serve as a communications channel and untangle the difficulties in the implementation phase. Find people who demonstrate leadership to enact the necessary changes. The system's multidimensional and dynamic mindset is key to achieving the necessary social, economic and cultural changes. Participatory experimentation with new forms of production from plant fibers is a strategy for the empowerment of the populations involved. Consequently, this leads to an improvement in the quality of life, measured not only in the economic aspect, but also by meeting people's needs for self-esteem and self-fulfillment.

\section{References}

Amaral, R. and Gutjahr, M. R. (2012) Desastres naturais, São Paulo: IG/ SMA. 
theme 4

technology strand 3

design and technology

Andrade, A.M. and Tatto, N. (ed.) (2013). Inventário Cultural Quilombola do Vale do Ribeira. São Paulo: Instituto Socioambiental.

Klintowitz, J. (1985) Trançado brasileiro. São Paulo: Rhodia.

Nelson, H. G. and E. Stolterman (2000). Design as Being in Service. Foundations for the Future; Doctoral Education in Design. D. Durling and K. Friedman. Staffordshire, GB, Staffordshire University Press: 23-33.

Sachs, I. (1993) Estratégias de transição para o século XXI: Desenvolvimento e meio ambiente, São Paulo: Studio Nobel, Fundação do Desenvolvimento Administrativo. 